\title{
Removal of three nitrophenols from aqueous solutions by adsorption onto char ash: equilibrium and kinetic modeling
}

\author{
Yehia M. Magdy ${ }^{1} \cdot$ Hossam Altaher ${ }^{2} \cdot$ E. ElQada $^{3}$
}

Received: 14 July 2017 / Accepted: 2 January 2018 / Published online: 30 January 2018

(C) The Author(s) 2018. This article is an open access publication

\begin{abstract}
In this research, the removal of 2,4 dinitrophenol, 2 nitrophenol and 4 nitrophenol from aqueous solution using char ash from animal bones was investigated using batch technique. Three 2-parameter isotherms (Freundlich, Langmuir, and Temkin) were applied to analyze the experimental data. Both linear and nonlinear regression analyses were performed for these models to estimate the isotherm parameters. Three 3-parameter isotherms (Redlich-Peterson, Sips, Toth) were also tested. Moreover, the kinetic data were tested using pseudo-first order, pseudo-second order, Elovich, Intraparticle diffusion and Boyd methods. Langmuir adsorption isotherm provided the best fit for the experimental data indicating monolayer adsorption. The maximum adsorption capacity was $8.624,7.55,7.384 \mathrm{mg} / \mathrm{g}$ for 2 nitrophenol, 2,4 dinitrophenol, and 4 nitrophenol, respectively. The experimental data fitted well to pseudo-second order model suggested a chemical nature of the adsorption process. The $R^{2}$ values for this model were 0.973 up to 0.999 . This result with supported by the Temkin model indicating heat of adsorption to be greater than $10 \mathrm{~kJ} / \mathrm{mol}$. The rate controlling step was intraparticle diffusion for 2 nitrophenol, and a combination of intraparticle diffusion and film diffusion for the other two phenols. The $\mathrm{pH}$ and temperature of solution were found to have a considerable effect, and the temperature indicated the exothermic nature of the adsorption process. The highest adsorption capacity was obtained at $\mathrm{pH} 9$ and $25^{\circ} \mathrm{C}$.
\end{abstract}

Keywords Adsorption $\cdot$ Char $\cdot$ Isotherms $\cdot$ Kinetic models $\cdot$ Phenols $\cdot$ Wastewater treatment

\section{Introduction}

Phenols are considered as priority pollutants by the US Environmental Protection Agency (EPA) and the European Union (USEPA 1987; Hamdaoui et al. 2005). This is because they have high toxicity even at low concentrations (Karimaei et al. 2017). The US Environmental Protection Agency (EPA) has set $1 \mathrm{mg} / \mathrm{L}$ as a limit for phenol content in wastewater (Larous and Meniai 2012). The maximum permissible limit of these compounds in water is $0.001 \mathrm{mg} / \mathrm{L}$ (Mubarik et al. 2012). Phenols have serious adverse effects

Hossam Altaher

haltaher@hotmail.com

1 Department of Chemical Engineering, Faculty of Engineering, El-Minia University, P.O. Box 61511, El-Minia, Egypt

2 College of Health Sciences, Jumeira University, P.O. Box 555532, Dubai, United Arab Emirates

3 Department of Chemical Engineering Technology, Yanbu Industrial College, P.O. Box 30436, Yanbu, Saudi Arabia on human beings including liver and kidney damage, protein degeneration, tissue erosion, pancreas damage, paralysis of the central nervous system, high blood pressure. Phenols may also cause high irritation to eyes, skin and mucous, headache and dizziness (Senturk et al. 2009; Păcurariu et al. 2013; Mukherjee and De 2014).

Phenols are released to the environment from the wastewater produced from many industries including paint, coal conversion, petroleum and petrochemical industries, polymeric resin, pesticides (Păcurariu et al. 2013; Mukherjee and De 2014).

Various processes have been investigated to treat wastewaters containing phenolic compounds. Existing technologies for the treatment are distillation, coagulation, electrocoagulation (Bazrafshan et al. 2012), biological treatment, catalytic oxidation, ozonation (Biglari et al. 2017), solvent extraction, and adsorption (Arana and Mazzoco 2010; Mubarik et al. 2012).

Among these methods, adsorption is preferred by many researchers and industries. It has many advantages over other treatment processes (Alipour et al. 2017). It can 
remove many types of pollutants even at very low concentration. It is not high energy consumption process and its design and operation is convenient (Zeng et al. 2009; liu et al. 2010).

Many adsorbents have been tested for the removal of phenols from water and wastewater. Examples of these adsorbent are activated carbon, zeolites, clay polymeric adsorbents (Li et al. 2013; Păcurariu et al. 2013). Several agricultural wastes have been investigated as potential adsorbents. Examples are saw dust (Larous and Meniai 2012), cumin straw ash (Rahdar et al. 2016), tea pulps ash (Saeidi et al. 2017), jute sticks (Mustafa et al. 2008), modified saxaul (Khaksefidi et al. 2016), Banana peel (Mandi et al. 2009; Rahdar et al. 2017), Allium sativum linn peel (Muthamilselvi et al. 2012), and tendu leaf refuse (Nagda et al. 2007). These biosorbents may have a serious adverse effect which is the possibility of leaching new organic pollutants to the treated water (Altaher 2014). The search for economic, efficient, and widely available adsorbent for the treatment of wastewater containing phenolic compounds is a must.

Many precursors are used for preparing activated carbon (Patel et al. 2015). The frequently used raw materials include coal, fruit stones, wood, polymer wastes, and bones (Purevsuren et al. 2004). When selecting the optimum precursors many factors must be taken into consideration including availability, efficiency of the produced activated carbon and the cost of the precursor.

Many factors play role in the adsorption process. Temperature, for instance, is a key player. If the adsorption takes place through physical processes (physical adsorption) then increasing the temperature will desorb the adsorbed molecules from the pore of adsorbent. On the other hand, increasing the temperature will decrease the viscosity which results in increasing of molecular motion. This mechanism will increase the uptake of molecules into the pores. The $\mathrm{pH}$ is another important factor that may affect the adsorption of pollutants on the surface of a surface adsorbent. The change in $\mathrm{pH}$ may affect both the status of the adsorbent by changing its surface charge enhancing or decreasing the adsorbability and also can affect the status of the adsorbate for example by hydrolysis or even precipitation. Contact time between adsorbent and adsorbate and mass of adsorbent are important parameters in designing the adsorption system.

The aim of this present work is to study the potential of char ash from animal bones for the removal of 2,4 nitrophenol, 2 nitrophenol and 4 nitrophenol from aqueous media. To accomplish this, equilibrium and kinetic study were performed. For equilibrium study three 2-parameter adsorption isotherms and three 3-parameter isotherms were applied. The kinetic study was performed to determine the rate and order of the reaction using pseudo-first order, pseudo-second order, and Elovich models. For determining the mechanism of the adsorption process, intraparticle and Boyd models were used. Parameters affecting the adsorption process such as $\mathrm{pH}$ and temperature were also considered.

\section{Materials and methods}

\section{Adsorbate}

The adsorbates used in this study were 2,4 nitrophenol, 2 nitrophenol, and 4 nitrophenol. These compounds were obtained from BDH Chemicals Ltd Poole, England (A.R. grade). They were used without any treatment. Stock solutions were prepared by dissolving the substance in bidistilled water. The working solutions were prepared by dilution with bidistilled water. The determination of these substances before and after adsorption was performed using Shimadzu UV-Vis Spectrophotometer, Japan. A calibration curve, at an appropriate wavelength, was prepared for each substance to help identifying the concentrations.

\section{Adsorbent}

The adsorbent which is an animal bone pyrolysis ash was prepared and characterized by Difullah et al. (1997). It was used without any further treatment. Characterization of this adsorbent was performed to identify its chemical and physical properties. In this concern, elemental analysis, screen analysis, and surface area measurements were applied.

\section{Experimental system}

The batch equilibrium experiments were made in Pyrex $125 \mathrm{~mL}$ glass conical flasks with stoppers. Different sets of these flasks were used for every adsorbate. To every flask containing $50 \mathrm{~mL}$ of the required adsorbate concentration $(5-60 \mathrm{mg} / \mathrm{L}), 1 \mathrm{~g}$ of adsorbent was added. The mixture was agitated at room temperature $\left(25^{\circ} \mathrm{C}\right)$ for $12 \mathrm{~h}$. The solutions were filtered and the final concentration was determined by spectrophotometer.

To determine the effect of time, a similar procedure was applied. However, to every flask containing $50 \mathrm{~mL}$ of the same adsorbate initial concentration $(40 \mathrm{mg} / \mathrm{L}), 1 \mathrm{~g}$ of adsorbent was added. Every flask was agitated at different time intervals (30-960 min). The experiments were also performed at room temperature. The final concentration of the adsorbate in every flask was determined. The effect of temperature on the adsorption process was studied at three temperatures $\left(25,35,45^{\circ} \mathrm{C}\right)$. Three sets of conical flasks containing $50 \mathrm{~mL}$ of the respective adsorbate solution (2,4 dinitrophenol, 2 nitrophenol and 4 nitrophenol) were prepared. The initial concentration of all solutions was adjusted at $40 \mathrm{mg} / \mathrm{L}$. To every flask, $1 \mathrm{~g}$ of adsorbent was added. The flasks were stoppered and the mixtures were agitated until equilibrium was attained. The solutions 
were filtered and the final concentrations of the adsorbate were determined. The effect $\mathrm{pH}$ was studied similarly but the $\mathrm{pH}$ of the solutions was adjusted using $\mathrm{HCl} / \mathrm{NaOH}$ at three $\mathrm{pH}$ values $(3,6$, and 9). The volume of the solution used was $50 \mathrm{~mL}$ in every flask and the amount of adsorbent added was $1 \mathrm{~g}$. All the experiments performed to study the $\mathrm{pH}$ were done at room temperature $\left(25^{\circ} \mathrm{C}\right)$.

\section{Adsorption isotherms}

The equilibrium data were fitted to several isotherm models to establish the most appropriate correlation for the adsorption system. These models were applied to fit the experimental equilibrium isotherm data of phenols adsorption on the adsorbent.

The adsorbate uptake at equilibrium, $q_{\mathrm{e}}(\mathrm{mg} / \mathrm{g})$, was determined using Eq. 1,

$q_{\mathrm{e}}=\left(C_{\mathrm{o}}-C_{\mathrm{e}}\right)(V / W)$,

where $C_{\mathrm{o}}$ and $C_{\mathrm{e}}(\mathrm{mg} / \mathrm{L})$ are the initial and equilibrium concentrations of the adsorbate, respectively, $V(\mathrm{~L})$ is the volume of the solution and $W(\mathrm{~g})$ is the mass of the adsorbent used.

\section{Langmuir isotherm (Altaher et al. 2015)}

The nonlinear model is given by the equation:

$q_{\mathrm{e}}=q_{\mathrm{m}} C_{\mathrm{e}} /\left(K+C_{\mathrm{e}}\right)$.

The linear form of this model is given by Eq. 3:

$1 / q_{\mathrm{e}}=1 /\left(q_{\mathrm{m}}\right)+C_{\mathrm{e}}\left(K_{\mathrm{L}} / q_{\mathrm{m}}\right)$,

where $C_{\mathrm{e}}(\mathrm{mg} / \mathrm{L})$ is the equilibrium concentration, $q_{\mathrm{e}}(\mathrm{mg} / \mathrm{g})$ is the adsorption capacity at equilibrium, $q_{\mathrm{m}}(\mathrm{mg} / \mathrm{g})$ is the maximum adsorption capacity, and $K_{\mathrm{L}}(\mathrm{L} / \mathrm{mg})$ is a constant related to adsorption rate. The favorability of the adsorption is given by the dimensionless separation factor $R_{\mathrm{L}}$ which is given by Eq. 4

$R_{\mathrm{L}}=1 /\left(1+K_{\mathrm{L}} C_{\mathrm{o}}\right)$,

where $C_{\mathrm{o}}(\mathrm{mg} / \mathrm{L})$ is the initial adsorbate concentration and $K_{\mathrm{L}}$ is Langmuir constant.

\section{Freundlich isotherm (Altaher et al. 2015)}

The nonlinear and linear forms of the isotherm are given by the following equations:

$q_{\mathrm{e}}=k_{\mathrm{f}} C_{\mathrm{e}}^{1 / n}$

$\ln q_{\mathrm{e}}=\ln k_{\mathrm{f}}+1 / n\left(\ln C_{\mathrm{e}}\right)$,

where $q_{\mathrm{e}}$ and $C_{\mathrm{e}}$ have the same designation as Langmuir equation, $k_{\mathrm{f}}$ is a constant related to the bonding energy, and
$1 / n$ is identifying the adsorption intensity of adsorbate onto adsorbent. If the value of exponent $n$ is greater than 1 then the adsorption represents favorable adsorption conditions.

Temkin isotherm (Ibrahim and Sani 2014)

Temkin isotherm equation is given as

$q_{\mathrm{e}}=B_{\mathrm{T}} \ln \left(K_{\mathrm{T}} C_{\mathrm{e}}\right)$.

The linear form is given by

$q_{\mathrm{e}}=B_{\mathrm{T}}\left(\ln K_{\mathrm{T}}\right)+B_{\mathrm{T}} \ln \left(C_{\mathrm{e}}\right)$,

$B_{\mathrm{T}}=(R T) / b$,

where $q_{\mathrm{e}}(\mathrm{mg} / \mathrm{g})$ and $C_{\mathrm{e}}(\mathrm{mg} / \mathrm{L})$ are the same as in Langmuir equation, $R$ is the universal gas constant $(8.314 \mathrm{~J} / \mathrm{mol} \mathrm{K}), b$ $(\mathrm{J} / \mathrm{mol})$ is the Temkin isotherm constant related to the heat of adsorption and $\mathrm{T}$ is the absolute temperature $(\mathrm{K})$. The constant $K_{\mathrm{T}}(\mathrm{L} / \mathrm{mg})$ is the equilibrium binding constant, corresponding to maximum binding energy.

\section{Redlich-Peterson (Belhachemi and Addoun 2011)}

The equation representing the model is written as follows:

$q_{\mathrm{e}}=\frac{k_{\mathrm{R}} C_{\mathrm{e}}}{1+a_{\mathrm{R}} C_{\mathrm{e}}^{b_{\mathrm{R}}}}$,

where $K_{\mathrm{R}}(\mathrm{L} / \mathrm{g}), a_{\mathrm{R}}\left(\frac{\mathrm{L}}{\mathrm{mg}}\right)^{b_{\mathrm{R}}}$ and $b_{\mathrm{R}}$ are the isotherm constants. At low concentration, the model approximate to Henry's law, while at high concentration it is similar to Freundlich model.

\section{Toth isotherm (Hamdaoui and Naffrechoux 2007b)}

This model is suitable for systems having sub-monolayer coverage (Hua et al. 2013) and adsorption in heterogeneous systems (Foo and Hameed 2010). One very important feature of this model is that it satisfies the two end limits (low and high concentrations). The equation has the following form:

$q_{\mathrm{e}}=\frac{k_{t} C_{\mathrm{e}}}{\left(a_{t}+C_{\mathrm{e}}\right)^{1 / t}}$,

The parameters $K_{t}$ and $t$ are related to adsorbate-adsorbent pairs. The parameter $t$ characterizes the system heterogeneity and it is usually less than unity. When $t=1$, the isotherm reduces to Langmuir equation. $a_{t}(\mathrm{~L} / \mathrm{mg})$ is a constant related to surface coverage. 


\section{Sips model (Foo and Hameed 2010)}

The equation is presented as

$q_{\mathrm{e}}=\frac{q_{\mathrm{m}}\left(a_{\mathrm{s}} C_{\mathrm{e}}\right)^{n_{\mathrm{s}}}}{1+\left(a_{\mathrm{s}} C_{\mathrm{e}}\right)^{n_{\mathrm{s}}}}$

where $a_{\mathrm{s}}$ is a constant related to the adsorption equilibrium, $q_{\mathrm{m}}$ is the maximum adsorption capacity ( $\mathrm{mg} / \mathrm{g}$ ), and $n_{\mathrm{s}}$ is a constant that is specific to adsorption system. If the value of $n_{\mathrm{s}}$ is equal to 1 the Sips equation converges to Langmuir model. At low $C_{\mathrm{e}}$ values, the equation reduces to the Freundlich isotherm.

\section{Kinetic models}

Studying the kinetics of adsorption help determining the time required to reach equilibrium. This time is required in designing the batch adsorption systems. It also provides valuable information about the mechanism of adsorption and the rate determining step. To evaluate the kinetic data, some of the commonly used kinetic models were applied. Pseudo-first order and pseudo-second order were used to determine the rate of the adsorption process. Elovich model was used to determine the rate of the reaction and the nature of the adsorption process. Intraparticle diffusion model and Boyd model were applied to determine the rate limiting step.

\section{Pseudo-first order model (Ashour et al. 2015)}

The linear form of this model is given by

$\ln \left(q_{\mathrm{e}}-q_{t}\right)=\ln q_{\mathrm{e}}-k_{1} t$

where $q_{\mathrm{e}}(\mathrm{mg} / \mathrm{g})$ and $q_{t}(\mathrm{mg} / \mathrm{g})$ are the amounts of adsorbate adsorbed on the surface of the adsorbate at equilibrium and at any time $t(\mathrm{~min})$, respectively; and $k_{1}\left(\mathrm{~min}^{-1}\right)$ is the rate constant of the pseudo-first order equation.

\section{Pseudo-second order model (Ashour et al. 2015)}

The linear form is given by

$t / q_{t}=1 / k_{2} q_{\mathrm{m}}^{2}+t / q_{\mathrm{m}}$,

where $k_{2}(\mathrm{~g} / \mathrm{mg} \mathrm{min})$ is the rate constant of the pseudo-second order equation, $q_{\mathrm{m}}(\mathrm{mg} / \mathrm{g})$ is the maximum adsorption capacity, and $q_{t}(\mathrm{mg} / \mathrm{g})$ is the amount adsorbed at time $t(\mathrm{~min})$.

\section{Intraparticle diffusion model}

This model (Lorenc-Grabowska et al. 2013) considers the intraparticle diffusion as the rate controlling step for adsorption. It is given by the following equation:

$q_{t}=k_{\mathrm{id}} t^{0.5}+C$ where $q_{t}(\mathrm{mg} / \mathrm{g})$ is the amount adsorbed at time $t$ (min) and $k_{\text {id }}\left(\mathrm{mg} / \mathrm{g} \min ^{0.5}\right)$ is the rate constant for the intraparticle diffusion model.

\section{Elovich model (Khalil et al. 2016)}

A simplified linearized form of Elovich equation is expressed as follows:

$q_{t}=1 / B \ln (\alpha B)+1 / B \ln t$,

where $\alpha(\mathrm{mg} / \mathrm{g}$ min) is the initial adsorption rate and $B(\mathrm{~g} /$ $\mathrm{mg}$ ) is the adsorption constant related to the extent of the surface coverage and activation energy for chemisorptions.

\section{Boyd model}

This model (Altaher et al. 2014) is applied to distinguish between the pore and film diffusion and help determining the rate determining step. The model is expressed as

$B_{t}=-0.4977-\ln \left(1-q_{t} / q_{\mathrm{e}}\right)$,

where $B_{t}$ is the mathematical function of fractional attainment of equilibrium. If the plot of $B_{t}$ versus $t$ produces a straight line that passes through the origin, pore diffusion is the rate limiting step. Otherwise, the adsorption process is intraparticle diffusion controlled.

\section{Results and discussion}

\section{Characterization of adsorbent and adsorbates}

To assess the adsorption behavior of the adsorbent and adsorbates, it is important to determine their chemical and physical properties. The data introduced in Table 1 illustrate the different properties of the adsorbent and adsorbates. It is clear from the elemental analysis that the ash is the main constituent of this adsorbent. This is normal since animal bones are the precursor of the adsorbent. The presence of metals like $\mathrm{Cu}, \mathrm{Fe}$, and $\mathrm{Sr}$ will not cause any problem since the leaching test proved their concentrations to be lower than the permissible level according to the Egyptian standards.

\section{Adsorption equilibrium}

Adsorption isotherm is an important design tool that indicates the relation between adsorbate and adsorbent at equilibrium. It gives an indication about the maximum adsorption capacity for the adsorbate on adsorbent at certain conditions of temperature, $\mathrm{pH}$ and initial concentration of adsorbate. It also allows the researcher to identify the nature of adsorption process; physical or chemical and it gives insight into surface properties of adsorbent (Ho et al. 2002). 
Table 1 Properties of adsorbent and adsorbates (Difullah et al. 1997)

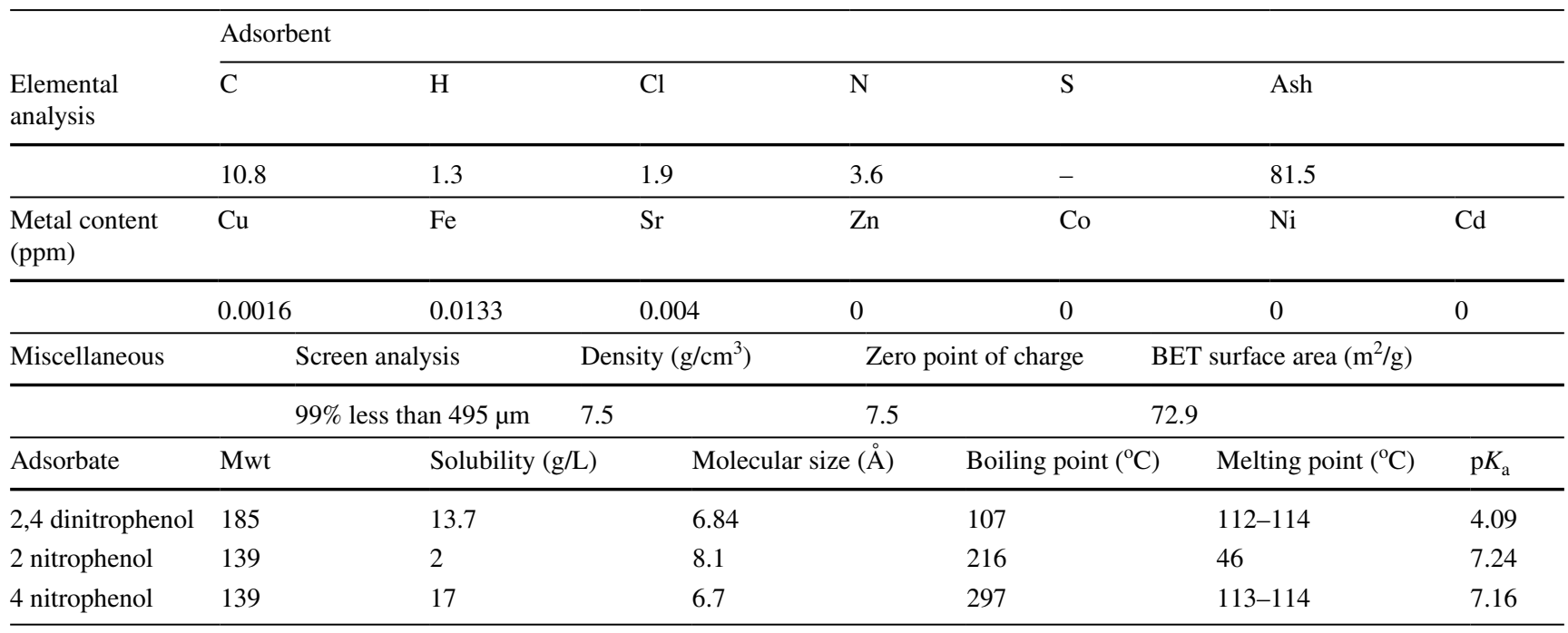

Fig. 1 Langmuir model for adsorption of phenols on char ash

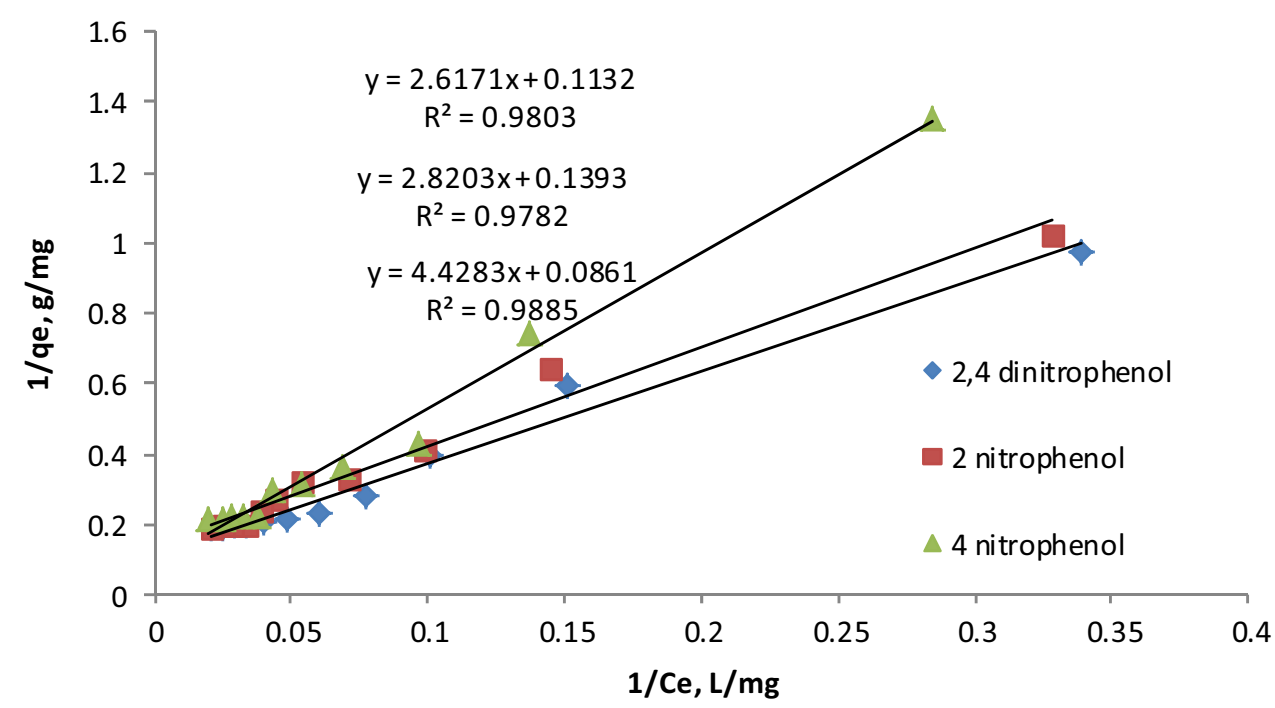

The experimental equilibrium data for adsorption of phenolic compounds on adsorbent was fitted to sets of isotherms; 2-parameter and 3-parameter isotherms. For 2-parameter isotherms, both linear and linear models were used for fitting. The errors in case of linear models were calculated using correlation coefficient $\left(R^{2}\right)$. For nonlinear fitting, square sum of error (SSD) was applied. The solver add-in function in Microsoft's spread sheet was used to minimize the error function (SSD).

\section{Two-parameter isotherm}

The linear fitting of the experimental data to Langmuir isotherm for the three phenols is presented in Fig. 1 and the constants calculated from this linear fitting are introduced in Table 2. The $R^{2}$ values for the three adsorbates are very high suggesting that the adsorption of the three phenols
Table 2 Linear adsorption constants for the applied two-parameter adsorption models

\begin{tabular}{lccc}
\hline Isotherm & 2,4 Dinitrophenol & 2 Nitrophenol & 4 Nitrophenol \\
\hline Langmuir & & & \\
$R^{2}$ & 0.98 & 0.978 & 0.988 \\
$q_{\mathrm{m}}$ & 8.85 & 7.20 & 11.63 \\
$K_{\mathrm{L}}$ & 23.26 & 20.28 & 52.63 \\
$R_{\mathrm{L}}$ & 0.279 & 0.253 & 0.467 \\
Freundlich & & & \\
$R^{2}$ & 0.921 & 0.974 & 0.939 \\
$n$ & 1.61 & 1.553 & 1.404 \\
$K_{\mathrm{f}}$ & 0.603 & 0.496 & 0.36 \\
Temkin & & & \\
$R^{2}$ & 0.956 & 0.94 & 0.961 \\
$B_{\mathrm{T}}$ & 1.855 & 1.757 & 1.744 \\
$K_{\mathrm{T}}$ & 0.499 & 0.425 & 0.363 \\
\hline
\end{tabular}


follows Langmuir model. Accordingly, the three adsorbates form a monolayer on the surface of adsorbent. Moreover, every molecule is adsorbed on a separate active site on the surface of adsorbent without any interaction between these molecules. The $R_{\mathrm{L}}$ values of 2,4 dinitrophenol, 2 nitrophenol and 4 nitrophenol are $0.279,0.25$, and 0.467 , respectively. Since $0<R_{\mathrm{L}}<1$ for the three adsorbates, the three adsorption systems are favorable.

It is clear from Table 2 that the adsorption capacity of 4 nitrophenol $(11.63 \mathrm{mg} / \mathrm{g})$ is higher than that of 2,4 dinitrophenol $(8.85 \mathrm{mg} / \mathrm{g})$ and 2 nitrophenol $(7.2 \mathrm{mg} / \mathrm{g})$. However, these values are different when fitting the experimental data to the nonlinear form of the isotherm.

The Langmuir constants obtained from the nonlinear analysis are presented in Table 3 . When comparing the constants obtained from both the linear and nonlinear equations for the three phenolic compounds, as indicated in Tables 2 and 3, we can notice that the transformation from linear to nonlinear model has resulted in a considerable change in the values of the constants and in the error structure (Ho et al. 2002). The same result can be obtained when comparing the plots representing the different models in Fig. 2. The nonlinear data is nearly superpositioned on the experimental data. Thus, it is more appropriate to use the constants obtained from the nonlinear model to characterize the adsorption of the three phenols on char ash. A similar result was obtained by Ho et al. (2002) and Hamdaoui and Naffrechoux (2007a) when studying the adsorption of heavy metals onto peat and phenol and chlorophenol on activated carbon, respectively. As presented in Table 3, maximum adsorption capacity of 2,4 dinitrophenol, 2 nitrophenol, and 4 nitrophenol are 7.55, 8.624 , and $7.384 \mathrm{mg} / \mathrm{g}$, respectively. These numbers are significantly different from that obtained from the linear fitting.

Table 3 Nonlinear adsorption constants for the applied two-parameter adsorption models

\begin{tabular}{lccc}
\hline Isotherm & 2,4 Dinitrophenol & 2 Nitrophenol & 4 Nitrophenol \\
\hline Langmuir & & & \\
$\mathrm{SSD}$ & 1.065 & 0.606 & 0.820 \\
$\mathrm{q}_{\mathrm{m}}$ & 7.55 & 8.624 & 7.384 \\
$K_{\mathrm{L}}$ & 15.873 & 27.778 & 23.810 \\
$R_{\mathrm{L}}$ & 0.209 & 0.316 & 0.284 \\
Freundlich & & & \\
$\mathrm{SSD}$ & 2.705 & 1.034 & 1.714 \\
$n$ & 2.161 & 1.769 & 1.849 \\
$K_{\mathrm{f}}$ & 0.996 & 0.640 & 0.631 \\
Temkin & & & \\
$\mathrm{SSD}$ & 1.236 & 1.153 & 0.834 \\
$B_{\mathrm{T}}$ & 1.765 & 1.742 & 1.674 \\
$K_{\mathrm{T}}$ & 0.539 & 0.431 & 0.384 \\
\hline
\end{tabular}
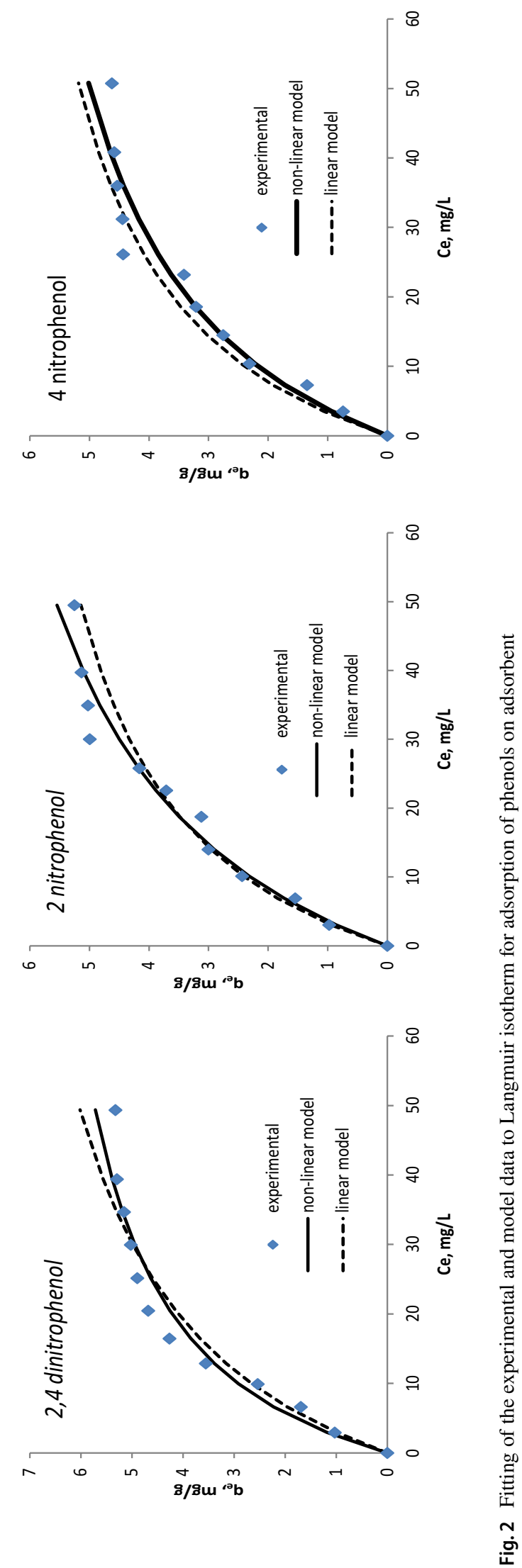
Fig. 3 Freundlich linear model for adsorption of phenols on char ash
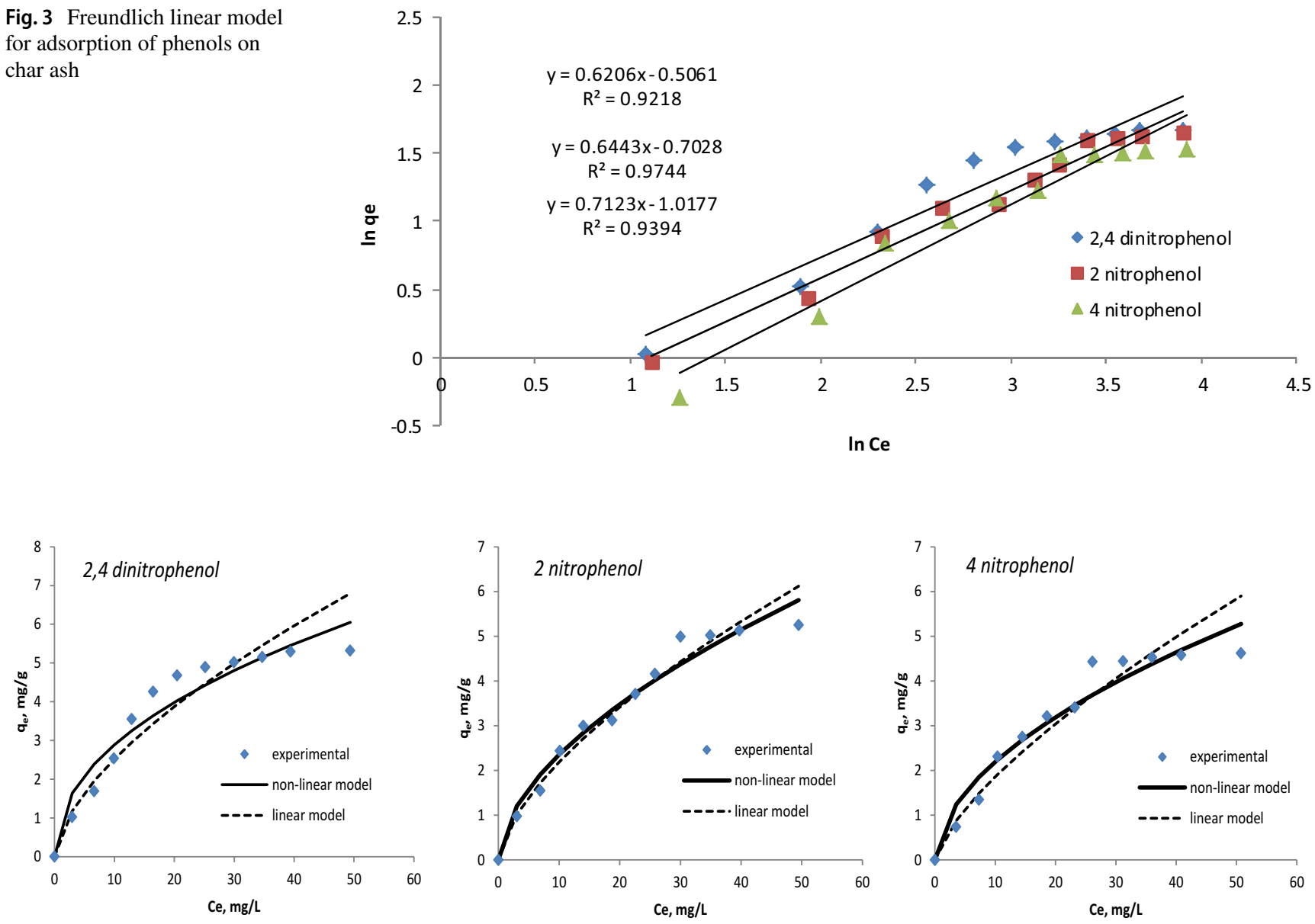

Fig. 4 Fitting of the experimental and model data to Freundlich isotherm for adsorption of phenols on char ash

Accordingly, the constants obtained from nonlinear fitting will be considered as the appropriate numbers. That means the order of the maximum adsorption capacity $\left(q_{\mathrm{m}}\right)$ follows the order: 2 nitrophenol $>2,4$ dinitrophenol $>4$ nitrophenol. This order agrees with that obtained from the kinetic data and will be discussed later on.

The plots obtained from fitting the experimental data to the linear form of Freundlich isotherm are introduced in Fig. 3 and the constants calculated from these plots are presented in Table 2. Examining the figures and data indicate good fitting of the experimental data to the model. The linear correlation coefficients $\left(R^{2}\right)$ of the 2,4 dinitrophenol, 2 nitrophenol, 4 nitrophenol are $0.921,0.974$, and 939, respectively. These numbers are reasonably high which again suggest good fitting especially for 2 nitrophenol. However, comparing these correlation coefficients with that obtained by fitting the experimental data to Langmuir model suggests that the later is more suitable for fitting the data.

The magnitude of the exponent $\mathrm{n}$ obtained from fitting the experimental data to Freundlich equation gives an indication about the favorability of the adsorption system. If the value

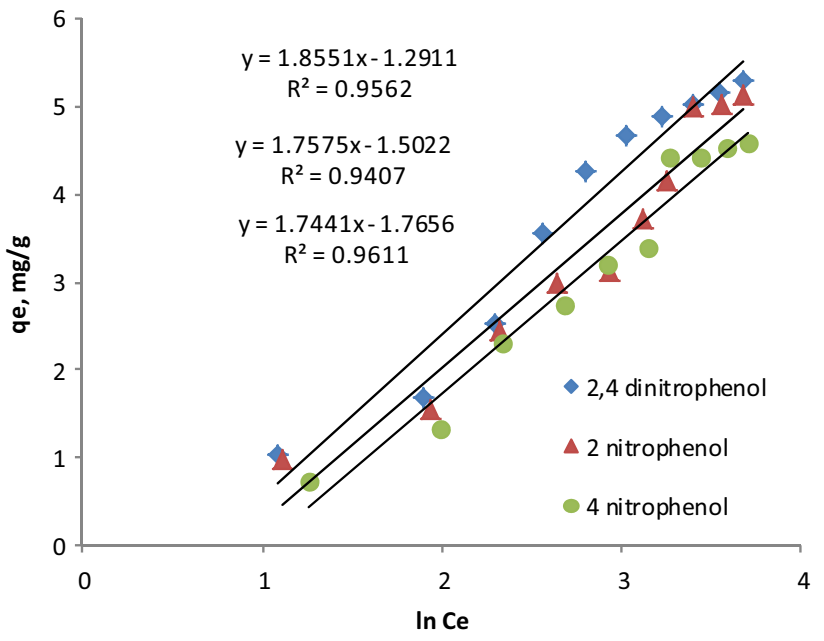

Fig. 5 Temkin model of phenols on char ash

of exponent $\mathrm{n}$ is greater than 1 then the adsorption represents favorable adsorption conditions. Examining the value of $n$ for the three phenols (Table 2), leads to the same conclusion 
obtained from Langmuir models. Since the value of $n$ for the three phenols is greater than 1, the char ash is a good adsorbent for these phenolic compounds.

The comparison of the experimental data to both linear and linear model (for the three phenols) is presented in Fig. 4. The plots in Fig. 4 show that the nonlinear fitting of 2 nitrophenol is better than that for 2,4 nitrophenol and 4 nitrophenol. This is supported by the values of SSD obtained from Table 3. The value of SSD in case of 2 nitrophenol is 1.034 compared to 2.705 and 1.74 for 2,4 dinitrophenol and 4 nitrophenol, respectively. Low value of SSD indicates better fitting of the data. The values of the parameter $n$ are still greater than one, which assure the favorability of adsorption of the three phenols on char ash.

Fitting of the experimental data to the linear for of Temkin isotherm is shown in Fig. 5. The parameters calculated from this linear fitting are introduced in Table 2. The figure and the high correlation coefficient values indicate that the model provides good fitting to the three adsorbates. The good fitting of the experimental data to the Temkin model indicates that the adsorption process depends on the heat of adsorption (Hanbali et al. 2014). The values of the parameter $\mathrm{b}$ in Temkin equation (related to heat of adsorption) are 12.5, 10.8 , and $11.21 \mathrm{~kJ} / \mathrm{mol}$ for 2,4 dinitrophenol, 2 nitrophenol, and 4 nitrophenol, respectively. These high values indicate the chemical nature of the adsorption process. Since these values are positive, the adsorption reaction is exothermic (Hamdaoui 2006).

Comparing the constants obtained from both linear and nonlinear models indicate that the linearization has a minor effect (also illustrated by Fig. 6). The deviation of the values of $B_{\mathrm{T}}$ obtained by the two methods is in the range of $0.5-5 \%$. The deviation of the values of $K_{\mathrm{T}}$ is in the range of 1.4-6\%. This means that both linear and nonlinear forms of Temkin isotherm can be used for fitting the experimental data (Ho et al. 2002).
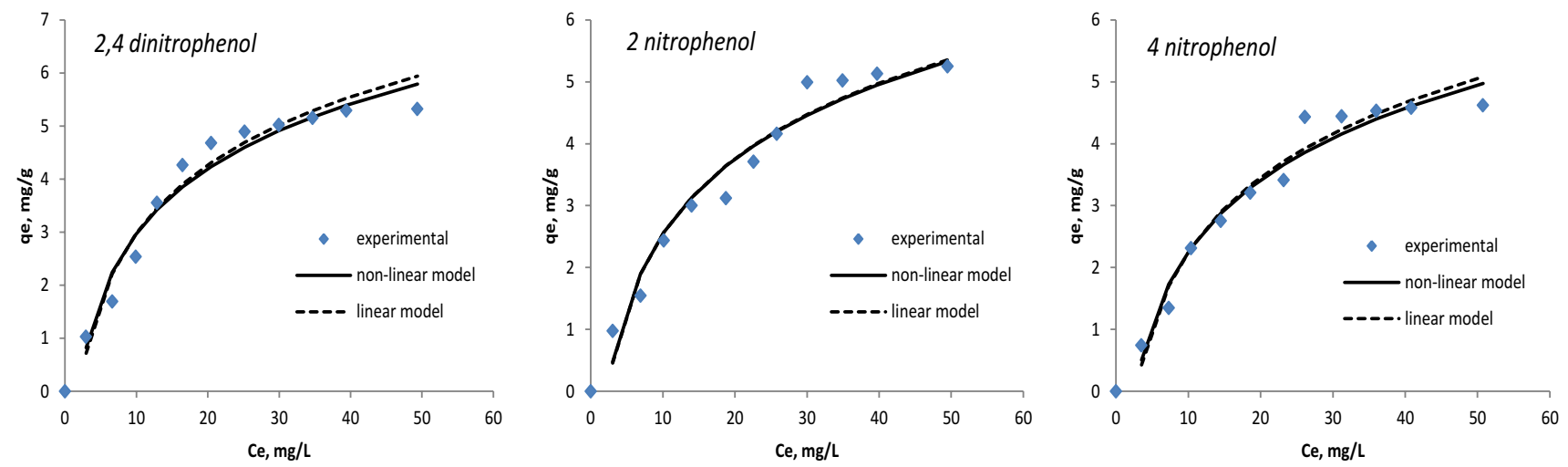

Fig. 6 Fitting of the experimental and model data to Temkin isotherm for adsorption of phenols on char ash

Fig. 7 Relation between adsorption capacity and molecular size of adsorbate

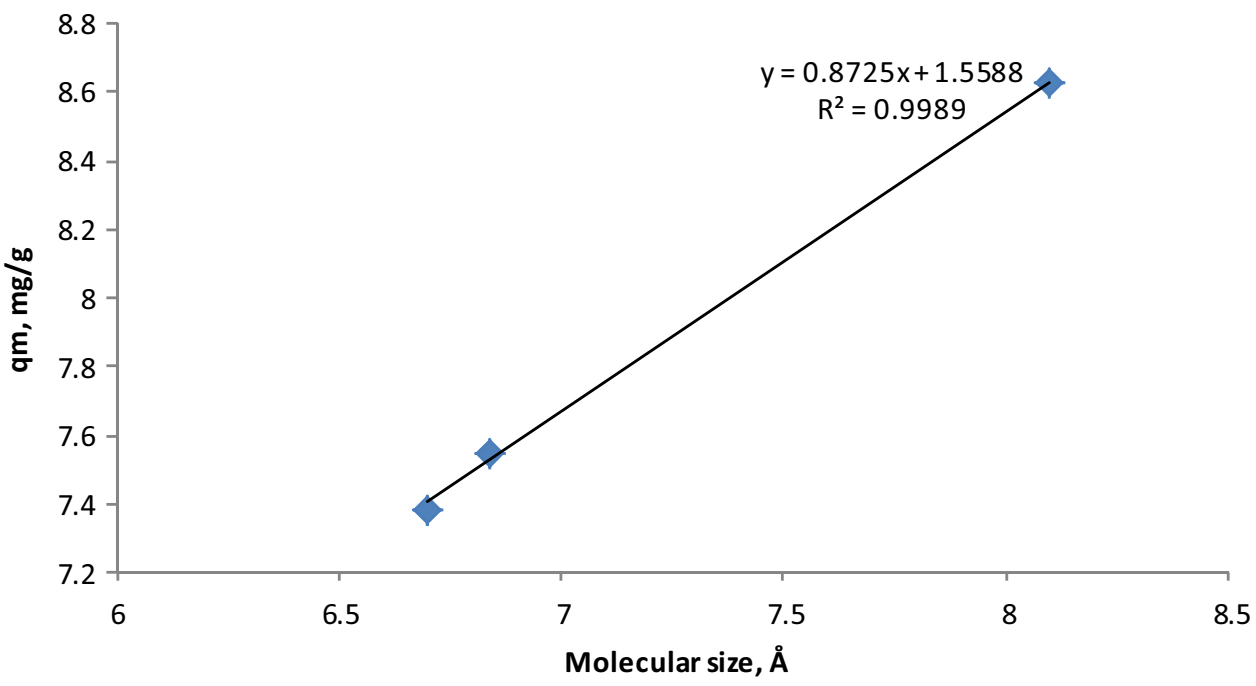


Many factors are responsible for the selective adsorption of a certain molecule on the surface of a certain adsorbent. From these factors, the molecular size, pore size and the interaction between the functional groups of adsorbate molecule and functional groups on the surface of adsorbent play important roles. The molecular size of adsorbate and the pore size of adsorbent must be comparable. If the molecular size is larger than the pore size, the steric effect will hinder the diffusion of the molecule inside the pore, thus decreasing the adsorption. Weak adsorption may also take place if the molecular size is much smaller than the pore size. In this case, desorption may take place especially if the adsorption process has a physical nature (Gokturk and Kaluc 2008; Liu et al. 2010; Mohamed 2011). Figure 7 illustrates the relation between the adsorption capacity of the three phenolic compounds and their molecular sizes. Increasing the molecular size of the phenol increases its adsorption capacity. The correlation coefficient of this phenomenon is very high (0.998). The high adsorption of 2 nitrophenol on the surface of char indicates the compatibility of the size of its molecules and the pore size of this adsorbent (Xiaohong et al. 2011).

Another factor that play important role in the adsorption process is the polarity of adsorbate. The adsorption of some adsorbate may take place because of their low polarity. In this case, they are rejected by the aqueous medium (Yonli et al. 2011; Carvajal-Bernal et al. 2015). 2 nitrophenol is less polar the 4 nitrophenol and as has been observed it has a higher maximum adsorption capacity. The same scenario can be applied when comparing 2 nitrophenol and 2,4 dinitrophenol.

Table 4 Nonlinear adsorption parameters for the applied threeparameter adsorption models

\begin{tabular}{clll}
\hline Isotherm & 2,4 Dinitrophenol & 2 Nitrophenol & 4 Nitrophenol \\
\hline \multicolumn{2}{l}{ Redlich-Peterson } & & \\
SSD & 2.705025 & 1.034224 & 1.713727 \\
$K_{\mathrm{R}}$ & 3153.906293 & 2876.966634 & 2855.930235 \\
$a_{\mathrm{R}}$ & 3167.36408 & 4497.052641 & 4525.102362 \\
$b_{\mathrm{R}}$ & 0.537207898 & 0.434694151 & 0.459154108 \\
Toth & & & \\
$\mathrm{SSD}$ & 0.51764 & 0.566836 & 0.59104 \\
$K_{\mathrm{T}}$ & 38999.00006 & 66.28798177 & 3837.002988 \\
$a_{\mathrm{T}}$ & 78.09352008 & 48.49430142 & 80.46230195 \\
$t$ & 0.379177565 & 0.716967813 & 0.460049318 \\
Sips & & & \\
SSD & 1.780349 & 0.93539 & 1.444713 \\
$q_{\mathrm{m}}$ & 7 & 8.048416709 & 6 \\
$a_{\mathrm{s}}$ & 0.081 & 0.041887224 & 0.07 \\
$n_{\mathrm{s}}$ & 0.9 & 0.9 & 0.99 \\
\hline
\end{tabular}

\section{Three-parameter isotherm}

The experimental data were analyzed according to the nonlinear form of Redlich-Peterson, Toth and Sips model. The nonlinear fitting will not cause any distortions in the error distribution since no transform has taken place in the dataset. Accordingly, better parameter estimate is expected (Belhachemi and Addoun 2011). The parameters obtained from this fitting are presented in Table 4 . The low SSD values obtained for the three adsorbates indicate good fitting of the experimental data to the model. According to the values of SSD for the fitting, Toth isotherm showed the best fitting (lowest SSD) followed by Sips and Redlich-Peterson comes last.

Toth isotherm is widely used to predict the monolayer adsorption (Whittaker 2015). This agrees with the previous result of Langmuir fitting which proved to be the suitable model that gives best fitting. As illustrated by Table 4 the values of $t$ for the three phenol are below 1 which is a condition of Toth isotherm. The parameter $t$ is considered to characterize the system heterogeneity. Deviation of this parameter from unity means the system is more heterogeneous (Hua et al. 2013). According to the value of $t$ in Table 4, the system is considerably homogeneous which again agrees with the previous results of fitting the data to Langmuir model. The value of $t$ in case of 2 nitrophenol is higher than that of two other phenols which indicates more homogeneity of this adsorption system. The maximum adsorption capacities (for the three phenols) determined using the Toth model are much higher than those of Langmuir. Even the order of this parameter changed from that introduced by linear and nonlinear Langmuir model (Tables 2, 3). It can be concluded, taking into consideration the values of SSD, that for fitting of the equilibrium adsorption data for the tested phenols the two parameter models are better than that of the three-parameter models.

On the basis of the values of SSD of the three phenolic compounds, Sips model provides weak fit of the experimental data. The reason maybe Sips equation is not valid at low concentration which means it cannot be applied on the whole tested concentration range (Terzyk et al. 2003). However, the values of the maximum adsorption capacity obtained using the Sips model are comparable to that obtained by nonlinear Langmuir equation and have the same order (2 nitrophenol $>2,4$ dinitrophenol and 4 nitrophenol). When $n_{\mathrm{s}}=1$, the Sips equation reduces to the Langmuir equation (Kumara et al. 2014).

As can be noticed in Table 4, the value of the exponent $n_{\mathrm{s}}$ is very close to unity $(0.9,0.9$, and 0.99 for 2,4 dinitrophenol, 2 nitrophenol, and 4 nitrophenol, respectively), which explains the values of $q_{\mathrm{m}}$ obtained from this model.

The Redlich-Peterson model clearly shows poor correlation (SSD for the three phenols are in the range 1.03-2) to the experimental data. The ratio $K_{\mathrm{r}} / A_{\mathrm{r}}(0.99,0.6397$, and 0.631 for 2,4 dinitrophenol, 2 nitrophenol, and 4 nitrophenol,

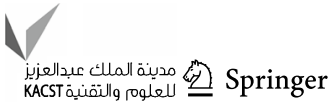


Fig. 8 Effect of contact time on adsorption of phenols on char ash

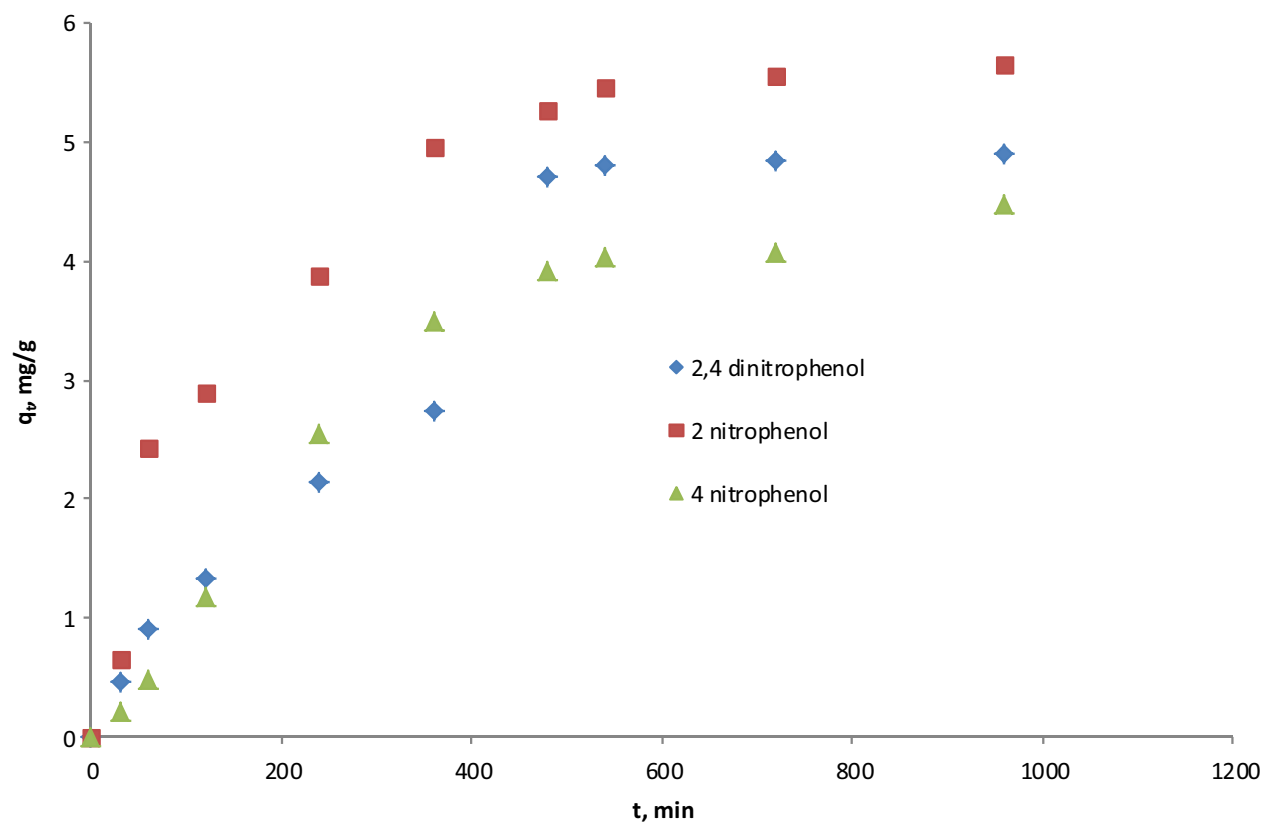

respectively) is identical to that of $K_{\mathrm{f}}$ obtained from the nonlinear fitting of the data to Freundlich model. However, the exponent $b_{R}$ does not have the same correspondence to the exponent $\mathrm{n}$ of Freundlich which is similar to that obtained by Hamdaoui and Naffrechoux (2007b). However, they are between 0 and 1 which indicate favorable adsorption.

\section{Kinetic study}

The study of kinetic results is useful in evaluating the quality of adsorbent, its efficiency for adsorbate removal, the rate of the adsorption reaction, the equilibrium time of the adsorption process and the mechanism of the adsorption. The relation between the contact time and adsorbate uptake $\left(q_{t}, \mathrm{mg} / \mathrm{g}\right)$ for the three phenolic compounds is introduced in Fig. 8. It is clear from the figure that the adsorption took place through two stages. In the initial stage $(3 \mathrm{~h})$, a sharp increase of adsorption was attained. This stage may be attributed to the high concentration gradient at the beginning of adsorption. This concentration gradient provides the driving force for the adsorption process to take place rapidly. In the second stage, the adsorption is slower since
Fig. 9 First order model of phenols on char ash

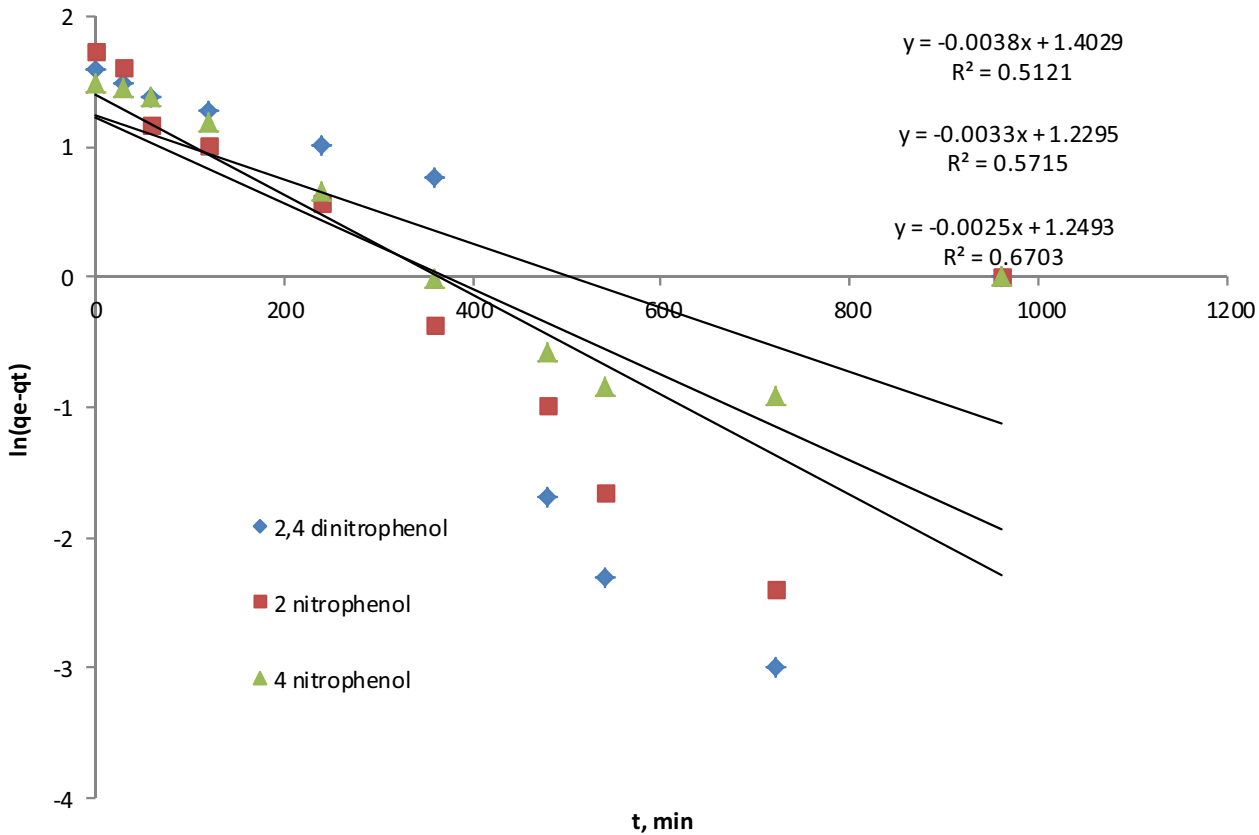


Table 5 Kinetic parameters for adsorption of phenols on char ash

\begin{tabular}{|c|c|c|c|}
\hline Kinetic model & 2,4 Dinitrophenol & 2 Nitrophenol & 4 Nitrophenol \\
\hline \multicolumn{4}{|c|}{ Pseudo-first order } \\
\hline$R^{2}$ & 0.512 & 0.571 & 0.670 \\
\hline$K_{1}$ & 0.003 & 0.003 & 0.002 \\
\hline$q_{\mathrm{e}}$ & 4.06 & 3.418 & 3.487 \\
\hline \multicolumn{4}{|l|}{$\begin{array}{l}\text { Pseudo-second } \\
\text { order }\end{array}$} \\
\hline \multicolumn{4}{|l|}{ Initial stage } \\
\hline$R^{2}$ & 0.973 & 0.973 & 0.993 \\
\hline$K_{2}$ & 1403 & 1231 & 1215 \\
\hline$q_{\mathrm{m}}$ & 4.85 & 6.94 & 2.88 \\
\hline \multicolumn{4}{|l|}{ Final stage } \\
\hline$R^{2}$ & 0.999 & - & 0.982 \\
\hline$K_{2}$ & 173 & - & 1386 \\
\hline$q_{\mathrm{m}}$ & 5.07 & - & 5.65 \\
\hline \multicolumn{4}{|l|}{ Elovich } \\
\hline \multicolumn{4}{|l|}{ Initial stage } \\
\hline$R^{2}$ & 0.964 & 0.877 & 0.940 \\
\hline$B$ & 1.101 & 1.05 & 1.453 \\
\hline$\alpha$ & 0.044 & 0.319 & 0.028 \\
\hline \multicolumn{4}{|l|}{ Final stage } \\
\hline$R^{2}$ & 0.904 & - & 0.905 \\
\hline$B$ & 4.15 & - & 0.769 \\
\hline$\alpha$ & 173,580 & - & 0.047 \\
\hline \multicolumn{4}{|c|}{$\begin{array}{l}\text { Intraparticle dif- } \\
\text { fusion }\end{array}$} \\
\hline$R^{2}$ & 0.926 & 0.918 & 0.941 \\
\hline$K_{\text {id }}$ & 0.191 & 0.201 & 0.174 \\
\hline$C$ & 0.417 & 0.419 & 0.371 \\
\hline \multicolumn{4}{|l|}{ Boyd } \\
\hline \multicolumn{4}{|l|}{ Initial stage } \\
\hline$R^{2}$ & 0.994 & 0.987 & 0.993 \\
\hline \multicolumn{4}{|l|}{ Final stage } \\
\hline$R^{2}$ & 0.94 & - & 0.997 \\
\hline
\end{tabular}

the molecules remaining in solution will compete for the remaining active sites. Equilibrium is attained after around $10 \mathrm{~h}$ where the rate of adsorption and desorption is equal. A similar result was obtained by Yaacoubi et al. (2015). The maximum adsorption capacity of adsorbates on the surface of adsorbent follows the order 2 nitrophenol $>2,4$ dinitrophenol $>4$ nitrophenol, which is the same order obtained from Langmuir adsorption isotherm.

\section{Rate equations}

The experimental data of the adsorption of the three phenolic compounds on adsorbent were fitted to the pseudofirst order and pseudo-second order equations. Figure 9 show the fitting of the experimental data to the pseudo-first order model and the calculated constants are introduced in Table 5. From the three plots it is clear that the data does not fit well to the pseudo-order model. This is indicated by the low values of the linear correlation coefficients $\left(R^{2}\right)$. On the other hand, fitting the data to the pseudo-second order equation, as illustrated by Fig. 10, show better fit with higher correlation coefficients. The plot of 2 nitrophenol indicates a single-stage adsorption process, while the plots of 2,4 dinitrophenol and 4 nitrophenol show two stages of adsorption; initial and final stages. So, multiple regressions were performed on these two stages to get two equations for each adsorption system. Every equation is valid for a single stage. These equations and their correlation coefficients are shown in Fig. 10 and Table 5. The linear correlation coefficients for all equations are highly significant and show a high degree of correlation between the experimental data and the pseudo-second order model. It is clear that the adsorption of these nitrophenols on adsorbent follows this model. This indicates the chemical nature of the adsorption process. This conclusion is supported by the values of $\mathrm{E}$ obtained from $\mathrm{D}-\mathrm{R}$ adsorption isotherm (data is not shown) which are higher than $10 \mathrm{~kJ} / \mathrm{mol}$ for the three adsorbates. The following of the phenolic compounds to the pseudo-second order
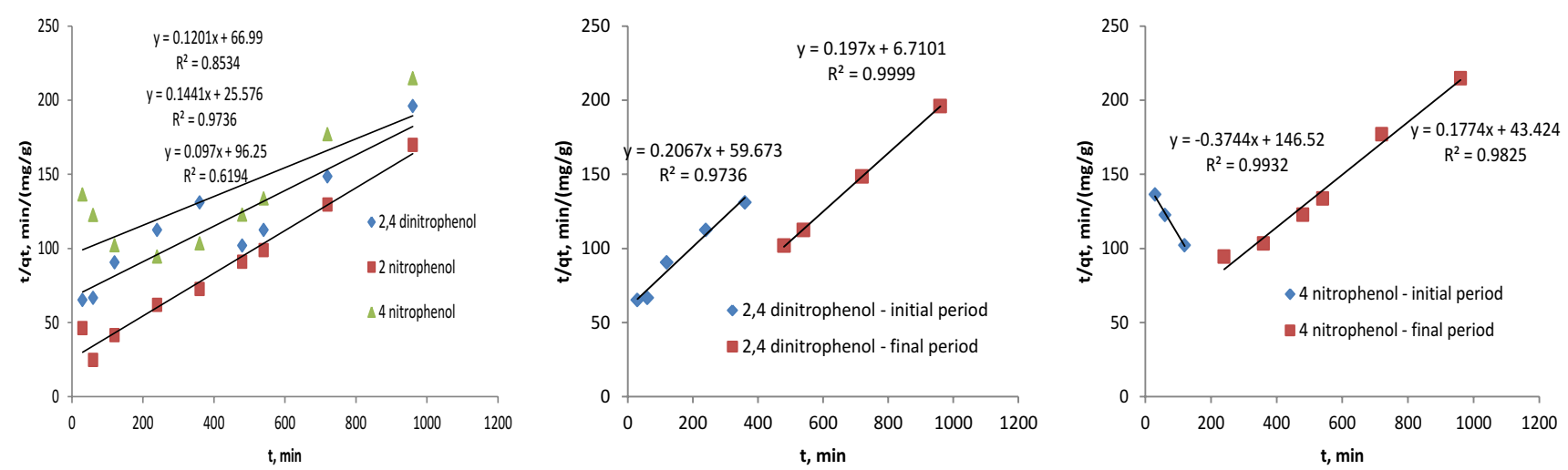

Fig. 10 Second order model of phenols on char ash 


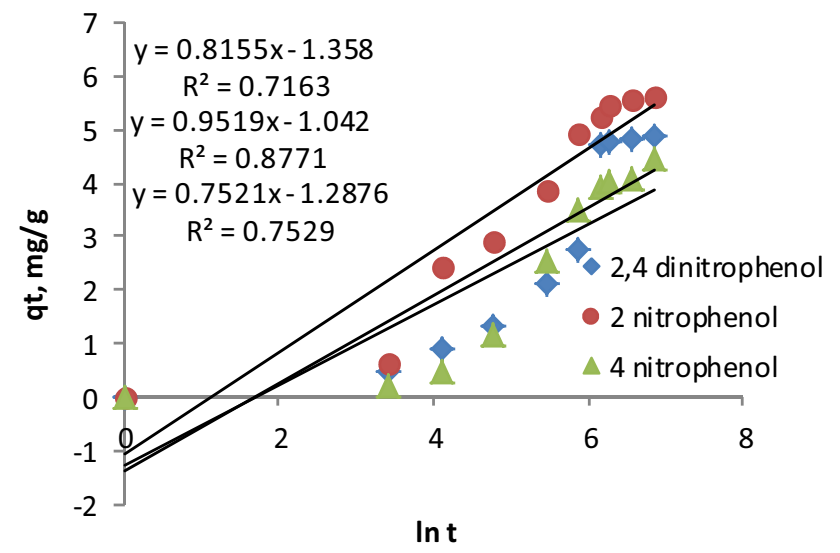

Fig. 11 Elovich model of phenols on char ash

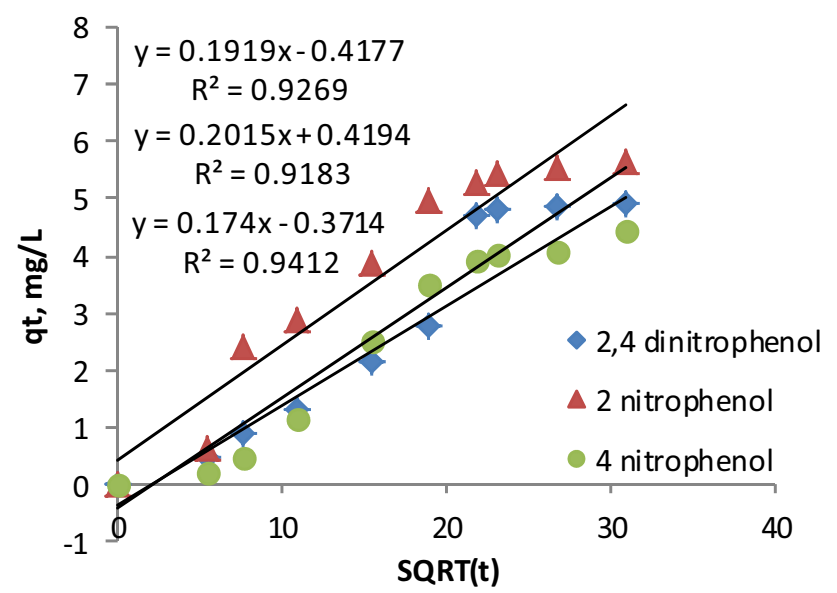

Fig. 12 Intraparticle modeling of the adsorption of phenols on char ash

model was observed by many other researchers (El-Sheikh et al. 2013; Altaher and Dietrich 2014; Masomi et al. 2014; Xiaohong et al. 2011).

\section{Elovich model}

Elovich equation does not provide a definite mechanistic of adsorption. However, if the experimental data fits well to this equation, then the adsorption process has a chemical nature.

Fitting of the experimental data to Elovich model is illustrated by Fig. 11 and the kinetics constants obtained from the equation are introduced in Table 5. It is clear that the data, for the three adsorbates, fits well to the modified Elovich equation. This is indicated by the high values of correlation coefficients.

It can be observed from the data in Table 5 that the values of $\alpha$ and $B$ varied from one adsorbate to another. For example, the value of $\alpha$ for 2 , nitrophenol is $0.319 \mathrm{mg} / \mathrm{g} \mathrm{min}$ compared to 0.044 and 0.028 for 2,4 dinitrophenol and 4 nitrophenol, respectively. As have been indicated before, $\alpha$ is related to the initial adsorption rate. This indicates the fast nature of adsorption of 2 nitrophenol compared to the other two adsorbates. This is in agreement with the results obtained from the second order model. Accordingly, we can conclude that the interaction of the three adsorbates with the adsorbent is chemisorption. The functional groups on the surface of adsorbent may interact with that in the adsorbates.

\section{Intraparticle and Boyd diffusion models}

It is important to determine the mechanism of the adsorption process. This will help controlling and designing the process. The adsorption takes place through four main stages (El-Sheikh et al. 2013). In the first stage, the adsorbate will migrate from the bulk of the solution until reaching the layer adjacent to the adsorbent particles. In the second and third stages, the molecules diffuse through the layer until reaching the adsorbent particles and through the pores on the surface of adsorbent. In the last stage, the adsorbate is adsorbed by the adsorbent. One or more of these stages control the adsorption process and is considered as the rate limiting step. The first and the last stages are usually fast and will not be taken into consideration when determining the rate limiting step. To identify which one of the remaining two steps are controlling the adsorption, two models are applied; intraparticle and Boyd diffusion models. Fitting the data to intraparticle diffusion model is performed by plotting $q_{t}$ against $t^{0.5}$. If a straight line passing through the origin is obtained, then intraparticle diffusion is the only mechanism responsible for adsorption. If the straight line is not passing through the origin, the adsorption is simultaneously controlled by two mechanisms. If the line obtained is not straight, then intraparticle diffusion is not controlling the adsorption. According to the Boyd model and similar to intraparticle diffusion model, if plotting $\ln \left(1-\left(q_{t} / q_{\mathrm{e}}\right)\right)$ against $t$ produces a straight line passing through the origin, then film diffusion is the only mechanism responsible for adsorption. The fitting of the experimental data to the two models is illustrated by Figs. 12 and 13. It is clear from the plot that the experimental data well fits Boyd model for 2 nitrophenol as illustrated by Fig. 13. The data produced straight line passing through the origin which indicates that the film diffusion is the only controlling step for the adsorption of 2 nitrophenol onto adsorbent. The other two phenols have a considerable good fit to intraparticle diffusion model. This is illustrated by the high correlation coefficients. However, the produced lines did not pass through the origin suggesting that another mechanism participate in controlling the adsorption. When drawing the Boyd plots for these two adsorbates and taking into consideration the two adsorption stages that have been mentioned before, straight lines with very high $R^{2}$ values were produced. That indicates that both 

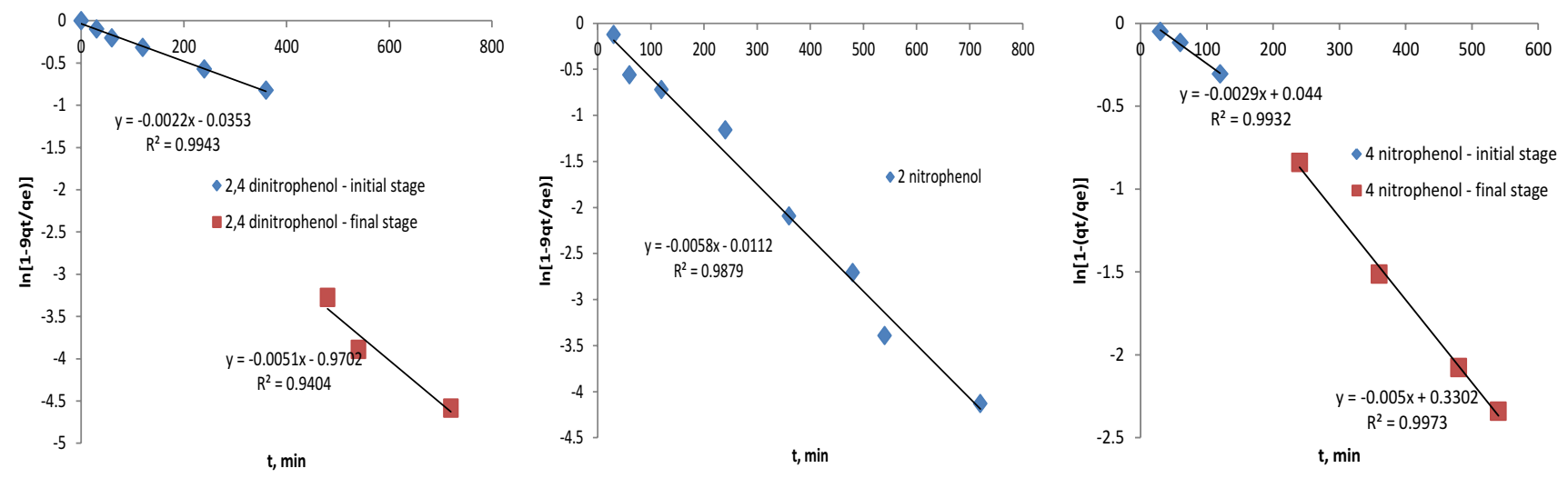

Fig. 13 Boyd plot for phenols adsorption onto char ash

Table 6 Effect of temperature on the adsorption capacity of phenolic compounds

\begin{tabular}{llll}
\hline Adsorption capacity & $25^{\circ} \mathrm{C}$ & $35^{\circ} \mathrm{C}$ & $45^{\circ} \mathrm{C}$ \\
\hline$q_{\mathrm{e}}, 2,4$ dinitrophenol & 6.905 & 5.960 & 4.315 \\
$q_{\mathrm{e}}, 2$ nitrophenol & 5.575 & 4.075 & 3.430 \\
$q_{\mathrm{e}}, 4$ nitrophenol & 6.275 & 4.850 & 3.790 \\
\hline
\end{tabular}

Table 7 Effect of $\mathrm{pH}$ on the adsorption capacity of phenolic compounds

\begin{tabular}{llll}
\hline Adsorption capacity & 3 & 6 & 9 \\
\hline$q_{\mathrm{e}}, 2,4$ dinitrophenol & 4.625 & 5.460 & 5.935 \\
$q_{\mathrm{e}}, 2$ nitrophenol & 3.705 & 4.852 & 6.911 \\
$q_{\mathrm{e}}, 4$ nitrophenol & 3.310 & 4.075 & 5.22 \\
\hline
\end{tabular}

intraparticle diffusion and film diffusion control the adsorption of 2,4 dinitrophenol and 4 nitrophenol onto char ash (El-Sheikh et al. 2013).

\section{Effect of temperature}

To study the effect of temperature, the adsorption of the three phenols was performed at three different temperatures; 25,35 , and $45^{\circ} \mathrm{C}$. The initial concentrations of the adsorbates were set at $40 \mathrm{mg} / \mathrm{L}$ and the solutions were agitated for $12 \mathrm{~h}$. The results are summarized in Table 6. It is clear that the adsorption capacity of the three phenols decreased with the increase in temperature. That means that the adsorption process has an exothermic nature. This result is in agreement with the result obtained from Temkin isotherm and that obtained by other researchers (Masomi et al. 2014).

\section{Effect of pH}

As indicated in Table 1, the zero point of charge of the adsorbent is 7.5. The surface of the adsorbent will be negatively charged at $\mathrm{pH}$ values greater than this value and positively charged at $\mathrm{pH}$ lower than this value. The $\mathrm{pKa}$ values of 2,4 dinitrophenol, 2 nitrophenol, 4 nitrophenol are 4.09, 7.24 , and 7.16, respectively. If the $\mathrm{pH}$ of the solutions is lower than $\mathrm{pKa}$, the adsorbate will be in the protonated state. So, at pHs 3 and 6 both adsorbent and adsorbate will have positive charge which causes electrostatic repulsion. This is clear from Table 7 where the lowest adsorption capacity was obtained at these acidic pHs. On the other hand, at $\mathrm{pH}$ 9, the adsorbates will be in the deprotonated state while the adsorbent will have a negative charge on the surface, thus increasing the adsorption capacity (Masomi et al. 2014).

\section{Conclusion}

This study was conducted to investigate the potential use of char ash prepared from animal bones to remove three phenols, namely 2,4 dinitrophenol, 2 nitrophenol, and 4 nitrophenol. The adsorption process was found to be favorable for the three adsorbate systems with 2,4 dinitrophenol having the highest adsorption capacity of $8.624 \mathrm{mg} / \mathrm{g}$. The best fit of the experimental data was using Langmuir adsorption isotherm $\left(R^{2}\right.$ value between 0.978 and 0.988$)$. The pseudosecond order model provided good fit for the adsorption of the phenolic compounds on the adsorbent $\left(R^{2}\right.$ value between 0.973 and 0.999). The rate limiting step for 2 nitrophenol was the intraparticle diffusion. On the other hand, both intraparticle diffusion and film diffusion were controlling the adsorption of 2,4 nitrophenol and 4 nitrophenol. Properties of adsorbate, adsorbent and adsorption system, viz. 
molecular size of adsorbate, $\mathrm{pKa}$ of adsorbate, point of zero charge of adsorbent, temperature and $\mathrm{pH}$ of adsorption system, were found to have considerable effect on the adsorption process. Highest adsorption was achieved at low temperature $\left(25^{\circ} \mathrm{C}\right)$ indicating the exothermic nature of the adsorption process. On the other hand, highest adsorption was obtained at $\mathrm{pH} 9$. Finally, Char ash produced from animal bones is a potential adsorbent to remove phenols from aqueous system. Further study is required to determine its ability to remove other pollutants.

Open Access This article is distributed under the terms of the Creative Commons Attribution 4.0 International License (http://creativecomm ons.org/licenses/by/4.0/), which permits unrestricted use, distribution, and reproduction in any medium, provided you give appropriate credit to the original author(s) and the source, provide a link to the Creative Commons license, and indicate if changes were made.

\section{References}

Alipour V, Etesamirad M, Rahdar S, Narooie M, Salimi A, Hasani J, Khaksefidi R, Sadat S, Biglari H (2017) Introduction of red soil (ocher) of hormoz Island as a natural adsorbent to removal of cadmium from aqueous solutions. J Global Pharma Technol 9(1):17-24

Altaher H (2014) Preliminary study of the effect of using biosorbents on the pollution of the treated water. Global NEST J 16(4):707-718

Altaher H, Dietrich AM (2014) Characterizing $o$ - and $p$-nitrophenols adsorption onto innovative activated carbon prepared from date pits. Water Sci Techol 69(1):31-37

Altaher H, Khalil TE, Abubeah R (2014) The effect of dye chemical structure on adsorption on activated carbon: a comparative study. Color Technol 130:205-214

Altaher H, Al-Oufi F, Magdy YH, Hassan M (2015) Microwave against thermal treatment for manufacturing of activated carbon from agricultural wastes and its use to adsorb methylene blue- equilibrium and kinetic studies. Yanbu J Eng Sci 11:29-42

Arana J, Mazzoco RR (2010) Adsorption studies of methylene blue and phenol onto black stone cherries prepared by chemical activation. J Hazard Mater 180:656-661

Ashour I, Altaher H, Sawalha F, Maraqah M (2015) A comparative study for the treatment of refinery synthetic wastewater containing phenol. Sci Technol Develop 34(1):16-26

Bazrafshan E, Biglari H, Mahvi A (2012) Phenol removal by electrocoagulation process from aqueous solutions. Fresenius Environ Bull 21:364-371

Belhachemi M, Addoun F (2011) Comparative adsorption isotherms and modeling of methylene blue onto activated carbons. Appl Water Sci 1:111-117

Biglari H, Afsharnia M, Alipour V, Khosravi R, Sharafi K, Mahvi A (2017) A review and investigation of the effect of nanophotocatalytic ozonation process for phenolic compound removal from real effluent of pulp and paper industry. Environ Sci Pollut Res 24:4105-4116

Carvajal-Bernal AM, Gómez F, Giraldo L, MorenoPiraján JC (2015) Chemical modification of activated carbons and its effect on the adsorption of phenolic compounds. Ingeniería y Competitividad 17(1):109-119
Difullah A, El-Reefy S, Gad H (1997) Adsorption of p-nitrophenol on Inshas incinerator ash and on the pyrolysis residue of animal bones. Adsorpt Sci Technol 15(7):485-496

El-Sheikh AH, Newman AP, Said AJ, Alzawahreh AM, Abu-Helal MM (2013) Improving the adsorption efficiency of phenolic compounds into olive wood biosorbents by pre-washing with organic solvents: equilibrium, kinetic and thermodynamic aspects. J Environ Manag 118:1-10

Foo KY, Hameed BH (2010) Insights into the modeling of adsorption isotherm systems. Chem Eng J 156:2-10

Gokturk S, Kaluc S (2008) Removal of selected organic compounds in aqueous solutions by activated carbon. J Environ Sci Technol $1: 111-123$

Hamdaoui O (2006) Batch study of liquid-phase adsorption of methylene blue using cedar sawdust and crushed brick. J Hazard Mater 35:267-273

Hamdaoui O, Naffrechoux E (2007a) Modeling of adsorption isotherms of phenol and chlorophenols onto granular activated carbon Part I. Two-parameter models and equations allowing determination of thermodynamic parameters. J Hazard Mater 147:381-394

Hamdaoui O, Naffrechoux E (2007b) Modeling of adsorption isotherms of phenol and chlorophenols onto granular activated carbon Part II. Models with more than two parameters. J Hazard Mater 147:401-411

Hamdaoui O, Naffrechoux E, Suptil J, Fachinger C (2005) Ultrasonic desorption of $p$-chlorophenol from granular activated carbon. Chem Eng J 106:153-161

Hanbali M, Holail H, Hammud H (2014) Remediation of lead by pretreated red algae: adsorption isotherm, kinetic, column modeling and simulation studies. Green Chem Lett Rev 7(4):342-358

Ho YS, Porter JF, Mckay G (2002) Equilibrium isotherm studies for the sorption of divalent metal ions onto peat: copper, nickel and lead single component systems. Water Air Soil Pollut 141:1-33

Hua C, Zong-Xin W, Mei-Sheng Y, Shi-Yi G (2013) Experimental investigation and modeling of adsorption of carbon dioxide on 5 a molecular sieve for helium purification of high-temperature gas-cooled reactor. Energy Proced 39:208-226

Ibrahim MB, Sani S (2014) Comparative isotherms studies on adsorptive removal of congo red from wastewater by watermelon rinds and neem-tree leaves. Open J Phys Chem 4:139-146

Karimaei M, Sharafi K, Moradi M, Ghaffari H, Biglari H, Arfaeinia H, Fattahi N (2017) Optimization of a methodology for simultaneous determination of twelve chlorophenols in environmental water samples using: In situ derivatization and continuous sample drop flow microextraction combined with gas chromatographyelectron-capture detection. Anal Methods 9:2865-2872

Khaksefidi R, Biglari H, Rahdar S, Baneshi M, Ahamadabadi M, Narooie M, Salimi A, Saeidi M, Alipour V (2016) The removal of phenol from aqueous solutions using modified saxaul ASH. Res J Appl Sci 11:1404-1410

Khalil TE, Altaher H, Reda Abubea R (2016) Adsorptive removal of $\mathrm{Cu}$ (ii) ions by date pits: kinetic and equilibrium studies. Environ Eng Manag J 15(12):2719-2732

Kumara N, Hamdan N, Petra MI, Tennakoon KU, Ekanayake P (2014) Equilibrium isotherm studies of adsorption of pigments extracted from kuduk-kuduk (Melastoma malabathricum L.) pulp onto TiO2 nanoparticles. J Chem 2014:1-6

Larous S, Meniai A-H (2012) The use of sawdust as by product adsorbent of organic pollutant from wastewater: adsorption of phenol. Energy Proced 18:905-914

Li C, Xu M, Sun X, Han S, Wu X, Liu Y, Huang J, Deng S (2013) Chemical modification of Amberlite XAD-4 by carbonyl groups for phenol adsorption from wastewater. Chem Eng J 229:20-26 
Liu Q, Zheng T, Wang P, Jiang J, Li N (2010) Adsorption isotherm, kinetic and mechanism studies of some substituted phenols on activated carbon fibers. Chem Eng J 157:348-356

Lorenc-Grabowska E, Gryglewicz G, Diez MA (2013) Kinetics and equilibrium study of phenol adsorption on nitrogen-enriched activated carbons. Fuel 114:235-243

Mandi L, Achak M, Hafidi A, Ouazzan IN (2009) Low cost bio-sorbent for the removal of phenolic compounds from olive mill wastewater. In: El Moujabber M, Mandi L, Trisorio-Liuzzi G, Martín I, Rabi A, Rodríguez R (eds) Technological perspectives for rational use of water resources in the mediterranean region. Bari: CIHEAM, 2009. pp 179-186 (Options Méditerran éennes: Série A. Séminaires Méditerranéens; $\mathbf{n} .88$ )

Masomi M, Ghoreyshi AA, Najafpour GD, Mohamed AR (2014) Adsorption of phenolic compounds onto the activated carbon synthesized from pulp and paper mill sludge: equilibrium isotherm, kinetics, thermodynamics and mechanism studies. IJE Trans A Basics 27(10):1485-1494

Mohamed EF (2011) Removal of organic compounds from water by adsorption and photocatalytic oxidation. Thesis, University of Toulouse

Mubarik S, Saeed A, Mehmood Z, Iqbal M (2012) Phenol adsorption by charred sawdust of sheesham (Indian rosewood; Dalbergia sissoo) from single, binary and ternary contaminated solutions. J Taiwan Inst Chem Eng 43:926-933

Mukherjee R, De S (2014) Adsorptive removal of phenolic compounds using cellulose acetate phthalate-alumina nanoparticle mixed matrix membrane. J Hazard Mater 265:8-19

Mustafa AI, Alam M, Amin M, Bahadur NM, Habib M (2008) Phenol removal from aqueous system by jute stick. Pak J Anal Environ Chem 9(2):92-95

Muthamilselvi P, Balamurugan P, Karthikeyan DR (2012) Adsorption of phenol from aqueous solution by allium sativum linn peel. Int J Eng Res App (IJERA) 2(5):727-731

Nagda GK, Diwan AM, Ghole VS (2007) Potential of Tendu leaf refuse for phenol removal in aqueous systems. Appl Ecol Environ Res $5(2): 1-9$

Păcurariu C, Mihoc G, Popa A, Muntean SG, Ianos R (2013) Adsorption of phenol and $p$-chlorophenol from aqueous solutions on poly (styrene-co-divinylbenzene) functionalized materials. Chem Eng J 222:218-227

Patel S, Han J, Qiu W, Gao W (2015) Synthesis and characterization of mesoporous bone char obtained by pyrolysis of animal bones, for environmental application. J Environ Chem Eng 3:2368-2377
Purevsuren B, Avid B, Gerelmaa T, Ya Davaajav, Morgan Y, Herod A, Kandiyoti R (2004) The characterisation of tar from the pyrolysis of animal bones. Fuel 83:799-805

Rahdar S, Khaksefidi R, Alipour V, Saeidi M, Narooie M, Salimi A, Biglari H, Baneshi M, Ahamadabadi M (2016) Phenol adsorptive by cumin straw ash from aqueous environments. IIOAB J 7:536-541

Rahdar S, Ahamadabadi M, Khaksefidi R, Saeidi M, Narooie M, Salimi A, Biglari H, Baneshi M (2017) Evaluation of phenol removal from aqueous solution by banana leaf ash. J Global Pharma Technol 9:20-28

Saeidi M, Biglari H, Rahdar S, Baneshi M, Ahamadabadi M, Narooie M, Salimi A, Khaksefidi R (2017) The adsorptive acid orange 7 using Kenya tea pulps ash from aqueous environments. J Global Pharma Technol 9:13-19

Senturk HB, Ozdes D, Gundogdu A, Duran C, Soylak M (2009) Removal of phenol from aqueous solutions by adsorption onto organomodified Tirebolu bentonite: equilibrium, kinetic and thermodynamic study. J Hazard Mater 172:353-362

Terzyk AP, Chatłas J, Gauden PA, Rychlicki G, Kowalczyk P (2003) Developing the solution analogue of the Toth adsorption isotherm equation. J Colloid Interface Sci 266:473-476

USEPA (1987) Federal Register, vol 52, no 131, USEPA, Washington, DC, pp 25861-25962

Whittaker PB (2015), Predicting the heats of adsorption for gas physisorption from isotherm measurement, Thesis, The University of Western Australia

Xiaohong L, Baowei Z, Kun Z, Xuekui H (2011) Removal of nitrophenols by adsorption using $\beta$-cyclodextrin modified zeolites. Chin J Chem Eng 19(6):938-943

Yaacoubi H, Songlin Z, Mouflih M, Gourai M, Sebti S (2015) Adsorption isotherm, kinetic and mechanism studies of 2-nitrophenol on sedimentary phosphate. Mediterranean J Chem 4(4):289-296

Yonli AH, Khalid M, Batonneau-Gener I, Koulidiati J, Joly G, Magnoux P, Mignard S (2011) Removal of phenolic pollutants from water over BEA and HY Zeolites in batch conditions. J Chem Chem Eng 5:429-434

Zeng X, Fan Y, Wu G, Wang C, Shi R (2009) Enhanced adsorption of phenol from water by a novel polar post-crosslinked polymeric adsorbent. J Hazard Mater 169:1022-1028

Publisher's Note Springer Nature remains neutral with regard to jurisdictional claims in published maps and institutional affiliations. 